\title{
Syndromic Surveillance on the Mental Health Impact of Political Rallies in Charlottesville, Virginia
}

\author{
Em Stephens* \\ Virginia Department of Health, Richmond, VA, USA
}

\section{Objective}

To describe the impact of civil unrest on the mental health of a community in near real-time using syndromic surveillance.

\section{Introduction}

As part of a wide-spread community discussion on the presence of monuments to Confederate Civil War figures, the Charlottesville city council voted to remove a statue of General Robert E. Lee. ${ }^{1}$ Multiple rallies were then held to protest the statue's removal. A Ku Klux Klan (KKK) rally on July 8, 2017 (MMWR Week 27) and a Unite the Right rally on August 12, 2017 (MMWR Week 32) held in Charlottesville both resulted in violence and media attention. ${ }^{2,3}$ The violence associated with the Unite the Right rally included fatalities connected to motor vehicle and helicopter crashes.

Syndromic surveillance has been used to study the impact of terrorism on a community's mental health ${ }^{4}$ while more traditional data sources have looked at the impact of racially-charged civil unrest. ${ }^{5}$ Syndromic surveillance, however, has not previously been used to document the effect of racially-charged violence on the health of a community.

\section{Methods}

The Virginia Department of Health (VDH) analyzed syndromic surveillance data from three emergency departments (EDs) in the Charlottesville area (defined to include Charlottesville city and Albemarle county), regardless of patient residence following the Unite the Right rally. Visits to these EDs between January 1 and September 2, 2017 were analyzed using the Enhanced Surveillance System for the Early Notification of Community-based Epidemics (ESSENCE) and Microsoft SQL 2012. Encounters were identified as acute anxiety-related visits based on an International Classification of Diseases, Tenth Revision (ICD-10) discharge diagnosis beginning with 'F41'. Analyses were conducted using the ESSENCE algorithm EWMA 1.2 and SAS 9.3.

\section{Results}

The greatest number of visits with a primary diagnosis of anxiety in $2017(\mathrm{~N}=20)$ was observed in MMWR week 34 (August 20-26). This represented a statistically significant increase over baseline with a $p$-value of 0.01 .

By race, a significant increase over baseline in visits with a primary diagnosis of anxiety was observed among blacks or African Americans. The largest volume of visits was observed in MMWR week 33 with a total of 8 identified visits or $1.8 \%$ of total ED visit volume. The increase in visits for anxiety observed in weeks 33-35 was 2.2 times greater among blacks or African Americans than it was among whites, $p=0.016,95 \%$ CI $[1.14,4.16]$.

\section{Conclusions}

Previous work done in Virginia to identify ED visits related to anxiety included only chief complaint criteria in the syndrome definition. Due to a change in how one ED in the Charlottesville area reported data during the study period, this syndrome definition could not be applied. In order to remove any potential data artifacts, only those visits with an initial diagnosis of anxiety were included in the analysis. The resulting syndrome definition likely underestimated the occurrence of anxiety in the Charlottesville area, both because it lacked chief complaint information and because syndromic surveillance does not include data on visits to mental health providers outside of EDs. This analysis presents a trend over time rather than a true measure of the prevalence of anxiety.

This analysis, while conservative in its inclusion criteria, still identified an increase in visits for anxiety, particularly among blacks or African Americans. In today's political environment of race-related civil unrest, a way to measure the burden of mental illness occurring in the community can be invaluable for public health response. In Charlottesville, the identification of a community-wide need for mental health support prompted many local providers to offer their services to those in need pro-bono. ${ }^{6}$

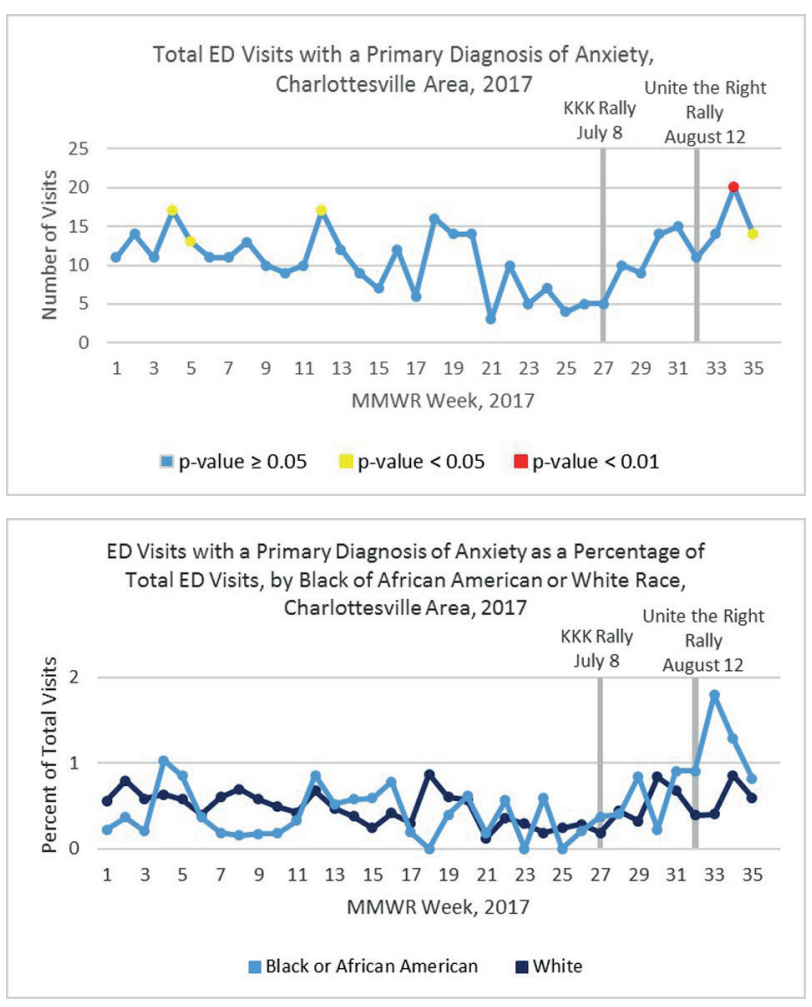

Keywords

Anxiety; Civil Unrest; Syndromic Surveillance

\section{Acknowledgments}

Many thanks to Erin Austin, MPH, Jonathan Falk, MPH, and Diane Woolard, $\mathrm{PhD}$ for the advice and review. 


\section{ISDS 2018 Conference Abstracts}

\section{References}

${ }^{1}$ Suarez, C. (2017, February 6). Charlottesville City Council votes to remove statue from Lee Park. The Daily Progress. Retrieved from http://bit.ly/2wYOHhv

${ }^{2}$ Spencer, H., \& Stevens, M. (2017, July 8). 23 Arrested and Tear Gas Deployed After a K.K.K. Rally in Virginia. The New York Times. Retrieved from http://nyti.ms/2tCiBGU

${ }^{3}$ Hanna, J., Hartung, K., Sayers, D., \& Almasy, S. (2017, August 13). Virginia governor to white nationalists: 'Go home ... shame on you'. CNN. Retrieved from http://cnn.it/2vvAGHt

${ }^{4}$ Vandentorren, S., Paty, A. C., Baffert, E., Chansard, P., CaserioSchönemann, C. (2016, February). Syndromic surveillance during the Paris terrorist attacks. The Lancet (387(10021), 846-847. doi:10.1016/ S0140-6736(16)00507-9

${ }^{5}$ Yimgang, D. P., Wang, Y., Paik, G., Hager, E. R., \& Black, M. M. Civil Unrest in the Context of Chronic Community Violence: Impact on Maternal Depressive Symptoms. American Journal of Public Health 107(9), 1455-1462. doi:10.2105/AJPH.2017.303876

${ }^{6}$ DeLuca, P. (2017, August 19). Downtown Charlottesville Library Offers Free Counseling. NBC29.com. Retrieved from http://bit.ly/2ylzHbl

\section{*Em Stephens}

E-mail: emily.stephens@vdh.virginia.gov 